\title{
Screening for Adolescent Depression among 11-14 Years School Going Children in Semi-Urban Chennai
}

\author{
V. Nandhanadevi ${ }^{1}$, Radha Kumar ${ }^{2}$ \\ ${ }^{1}$ Undergraduate Student, Department of Paediatrics, Saveetha Medical College Hospital, \\ Kuthambakkam, Chennai, Tamilnadu, India. \\ ${ }^{2}$ Professor, Department of Paediatrics, Saveetha Medical College Hospital, \\ Kuthambakkam, Chennai, Tamilnadu, India.
}

\section{ABSTRACT}

\section{BACKGROUND}

Adolescence refers to the transitional stage of physical and psychological development that marks the transformation from childhood to adulthood. They are unique with regards to their physical, mental and social problems. Depression in adolescents can be due to a myriad of reasons unique to the individual. Studies conducted in the past found males and older adolescents to express behaviour reflective of depression and adjustment difficulties when compared to their counterparts namely the females and the younger adolescents. Some studies have shown that depression in young individuals is heritable. Depression has several detrimental effects on an individual's physical and psychosocial development resulting in an incapacitated corollary constituting the society. Introversion and the existing illness behaviour with regards to mental illnesses is not favourable for early diagnosis and counselling. Thus, to counter the epidemic of sub-optimally functioning youth, crippled by mental distress, early diagnosis and interventions have to be made.

\section{METHODS}

This cross-sectional study was conducted with participants selected from a secondary school in Chennai, belonging to the age group of 11 to 14 years. 'Adolescent Well-Being Scale', a pretested questionnaire that screens adolescents for depression was used.

\section{RESULTS}

The results from the study show that $22.1 \%$ of female students were depressed and this is higher when compared to the percentage of depressed male students. $33 \%$ of 13 -year-old adolescents were found to be depressed. It found that $27.7 \%$ students without a sibling while $27 \%$ of students with sibling (s) had depression.

\section{CONCLUSIONS}

The study also shows a trend of rise in the occurrence of depression with age. Maintaining mental health demands a support system that serves as a mental cushion, aiding in coping and resilience with any stress or strains of life. Thus, timely identification and interventions allows an otherwise unattainable mirage, healthy adulthood.

\section{KEY WORDS}

Adolescents, Well-Being, Depression, Anxiety
Corresponding Author:

Radha Kumar,

B-4, Block-1, Sidharth Heights,

No. 55, Arcot Road, Saligramam,

Chennai-600093, Tamilnadu, India.

E-mail:drradhakumar68@gmail.com

DOI: $10.14260 / j e m d s / 2019 / 553$

Financial or Other Competing Interests: None.

How to Cite This Article:

Nandhanadevi V, Kumar R. Screening for adolescent depression among 11-14 years school going children in semi-urban Chennai. J. Evolution Med. Dent. Sci. 2019;8(32):2539-2543, DOI: $10.14260 /$ jemds/2019/553

Submission 15-06-2019,

Peer Review 25-07-2019,

Acceptance 01-08-2019,

Published 12-08-2019.

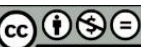




\section{BACKGROUND}

There is no better stage to prepare one for the ordeals of adult life than this quotidian powerful drama, the so-called adolescent life. Adolescence refers to the transitional stage of physical and psychological development that marks the transformation from childhood to adulthood. This period comprises of individuals belonging to the age group of 10 to 19 years who are unique with regards to physical, mental, emotional and social problems. Mental habits such as coping, and resilience are important to equip adolescents to accept changes of any kind around them. Some common problems of this demography include teenage pregnancy, delinquency, substance abuse, depression, sexual identity problems, learning disorders and eating disorders. Depression in adolescents can be due to physical and emotional abuse at home, bullying at school, maladaptation to new environment, diseases, post accidents /trauma, insecurities regarding appearance and that due to their social and economic status in the societal hierarchy, bereavement, peer pressure, academic stress and sexual identity problems. The rise in internet usage and subsequent addiction seals the possibility of social developmental skill by impeding interaction with family and friends.

Twin studies have shown that depression in young individuals is heritable.(1) A study conducted at Delhi using Mental Health Continuum Short Form, Depression Anxiety and Stress Scales-21 found girls and younger adolescents to be flourishing more compared to boys and older adolescents. Flourishing youths in turn had lesser prevalence of depression and adjustment difficulties, and exhibited prosocial behaviour.(2) A Korean study found that levels of depression and suicide ideation were highest in the Internet-addicts group.(3) An Iranian study also looked into social factors such as father's unemployment, mother's job and history of psychiatric hospitalization of either of the parents as possible predisposing factors for depression which revealed that fathers unemployment showed positive causal relation.(4)

Depression has several detrimental effects on an individual's psychosocial development. It takes a toll on one's academic results and nutritional status due to binge eating or anorexia nervosa. Depression has also been proven to affect memory and affect the optimal physical, mental and social functioning of an individual. An American study found that prevalence of conduct problems such as skipping school, alcohol use, marijuana use and cigarette smoking decreased while attributes of productive psychosocial functioning such as self-determination, closeness to others, and school integration increased as mental health increased.(5) According to Maslow's hierarchy of needs, self- actualisation borne through creativity and spontaneity is possible only when basic needs (Physiological and safety needs) and psychological needs are met with.

Depression in adolescents is often missed and it can be attributed to their irritable nature, mood reactivity, and fickle nature of the symptoms observed in them. Depression can also be missed if the primary presenting problems are unexplained, less specific physical symptoms, eating disorders, anxiety, refusal to attend school, decline in academic performance, substance misuse, or behavioral problems.(6) Most importantly illness behaviour with regards to mental illnesses is not favorable for early diagnosis and counselling.(7) Thus to counter the epidemic of sub-optimally functioning youth, crippled by mental distress, early diagnosis and interventions have to be made to avoid irreversible repercussions on their lives. Some commonly used questionnaires for early detection of depression are the Beck Depression Inventory, Mental health continuum short form Depression anxiety stress scale 21, Wang-Self-Assessing Depression Scale and Reynolds Adolescent Depression Scale. Harvard trauma questionnaire was used to assess prevalence of post-traumatic stress among the denizens of Kashmir Valley which was and still is under constant political and military scrutiny. The ClinicianAdministered PTSD Scale for Children and Adolescents (CAPSCA5) is a 30-item structured interview that assesses trauma exposure as well as PTSD symptoms for children above seven years of age. Questionnaire based studies are simple and effective in screening a large population. It suffers from the drawback of relying on the individual's subjective assessment of symptoms whose conceived threshold cannot be standardized.

\section{METHODS}

This cross-sectional study was conducted from January till March 2019. Participants of the study were selected from a secondary school in semi- urban Chennai, Tamil Nadu. Parental written informed consent and assent from the adolescent students belonging to the age group of 11 to 14 years were taken before including them as participants. The students of $6^{\text {th }}$ to $8^{\text {th }}$ grade belonging to the age group of 11 to 14 years were included in the study. A sample size of 191 was selected by convenience sampling. The process of acquiring relevant data for the study began after its approval by the IRB, SMCH.

The study tool used was a self-rating scale for detecting depression in children called 'Adolescent Well-being Scale'. The scale was administered to children included in the study and they were asked to read the statements and tick the answer that best described their feelings during past one week. Since the students belonged to English medium school, translation of the scale in local language was not done. This scale was invented by Peter Birleson in the 1978 to screen for depression among children. It has been modified and validated to evaluate adolescents between 11 to 16 years. The scale has adequate face validity and factorial validity. It has 18 items, each provided with responses most of the time, sometimes, never. The responses to each question are provided with scores 0,1 or 2 depending on the nature of the question. A score of 0 implies no concern, 1 possible concern and 2 that young person is indicating unhappiness or low self-esteem in the aspect of life enquired through the item. Based on the nature of questions they are broadly categorized into positive and negative items. Responses to each item can help understand privation and consequent need of the adolescent with regards the concerned aspect of life. This questionnaire has allowed for adolescents to gain an overall insight into their prevalent state of mind in a short time. A minimum score of 0 and a maximum of 36 can be obtained. A score above 13 is suggestive of possible depressive disorder. This is not a diagnostic tool and only allows for subjective evaluation or introspection into their feelings toward day to day life. The data collected was entered and quantified in excel 
spreadsheet. Statistical analysis was done using standard Chisquare test.

\section{RESULTS}

\begin{tabular}{|c|c|c|}
\hline & Number & Frequency (\%) \\
\hline Male & 96 & 50.261 \\
\hline Female & 95 & 49.738 \\
\hline Total & $\mathbf{1 9 1}$ & $\mathbf{1 0 0}$ \\
\hline \multicolumn{2}{|c|}{ Table 3.1. Sex Distribution of the Students } \\
\hline $\begin{array}{l}\text { 50.2\% of the study population are female students and the remaining are male } \\
\text { students. }\end{array}$
\end{tabular}

\begin{tabular}{|c|c|c|}
\hline Score & $<=13$ & $>\mathbf{1 3}$ \\
\hline Male & 79 & 17 \\
\hline Female & 74 & 21 \\
\hline Total & $\mathbf{1 5 3}$ & $\mathbf{3 8}$ \\
\hline \multicolumn{2}{|c|}{ Table 3.2. Sex Distribution of Depressed Students } \\
\hline $\begin{array}{l}17.70 \% \text { of male students and 22.10\% of female students had a score more than } 13 \\
\text { which is suggestive of possible depression. }\end{array}$
\end{tabular}

\begin{tabular}{|c|c|c|c|c|}
\hline Age (in Years) & $\mathbf{1 1}$-12 Yrs. & $\mathbf{1 2 - 1 3}$ Yrs. & 13-14 Yrs. & 14 Yrs. \\
\hline Male & 30 & 39 & 24 & 3 \\
\hline Female & 43 & 28 & 22 & 2 \\
\hline Total & 73 & 67 & 46 & 5 \\
\hline \multicolumn{4}{|c|}{ Table 3.3. Age Distribution of the Study Population } \\
\hline
\end{tabular}

\begin{tabular}{|c|c|c|}
\hline Age (in Years) & Score $>$ 13 & Frequency (\%) \\
\hline $11-12$ & 21 & $27.27 \%$ \\
\hline $12-13$ & 16 & $23.88 \%$ \\
\hline $13-14$ & 14 & $33.33 \%$ \\
\hline $14-15$ & 1 & $20 \%$ \\
\hline Table 3.4. Age Distribution of Depressed Students \\
\hline \multicolumn{3}{|c|}{ Thus, 27.27\% of 11 to 12 year olds and 33.33\% of 13 to 14 year olds had depression } \\
\hline
\end{tabular}

\begin{tabular}{|c|c|c|c|}
\hline Presence of Sibling (s) & & Score $>13$ & Percentage \\
\hline Yes & 137 & 37 & $27 \%$ \\
\hline No & 54 & 15 & $27.77 \%$ \\
\hline \multicolumn{2}{|c|}{ Table 3.5. Distribution of Depressed Students Having Siblings } \\
\hline $\begin{array}{l}\text { 27\% of students with siblings and } 27.77 \% \text { of students without siblings have a score } \\
\text { greater than 13 which is suggestive of depression. }\end{array}$
\end{tabular}

\begin{tabular}{|c|c|c|c|}
\hline Score & $\begin{array}{c}\text { 0 (Most of the } \\
\text { Time) }\end{array}$ & $\begin{array}{c}1 \\
\text { (Sometimes) }\end{array}$ & $\begin{array}{c}\mathbf{2} \\
\text { (Never) }\end{array}$ \\
\hline $\begin{array}{c}\text { Q1 I look forward to things as } \\
\text { much as I used to }\end{array}$ & $81(42.40 \%)$ & $96(50.26 \%)$ & $14(7.32 \%)$ \\
\hline Q2 I sleep very well & $100(52.35 \%)$ & $77(40.31 \%)$ & $14(7.32 \%)$ \\
\hline Q4 I like going out & $127(66.49 \%)$ & $58(30.36 \%)$ & $6(3.14 \%$ \\
\hline Q7 I have lots of energy & $106(55.49 \%)$ & $74(38.74 \%)$ & $11(5.75 \%)$ \\
\hline Q8 I enjoy my food & $128(67.01 \%)$ & $57(29.84 \%)$ & $6(3.14 \%)$ \\
\hline Q9 I can stick up for myself & $98(51.3 \%)$ & $77(40.31 \%)$ & $16(8.37 \%)$ \\
\hline Q11 I am good at things I do & $67(35.07 \%)$ & $67(35.07 \%)$ & $57(29.84 \%)$ \\
\hline $\begin{array}{c}\text { Q12 I enjoy things as much as I } \\
\text { used to }\end{array}$ & $116(60.73 \%)$ & $68(35.6 \%)$ & $7(3.66 \%)$ \\
\hline $\begin{array}{c}\text { Q13 I like talking to my friends } \\
\text { and family }\end{array}$ & $163(85.34 \%)$ & $25(13.08 \%)$ & $3(1.57 \%)$ \\
\hline Q16 I am easily cheered up & $92(48.16 \%)$ & $83(43.45 \%)$ & $16(8.37 \%)$ \\
\hline \multicolumn{4}{|c|}{ Table 3.6. Frequency of Responses to Positive Items } \\
\hline \multicolumn{4}{|c|}{}
\end{tabular}

\begin{tabular}{|c|c|c|c|}
\hline Questions & $\begin{array}{c}0 \text { (Never) } \\
\text { in } \%\end{array}$ & $\begin{array}{c}1 \text { (Sometimes) } \\
\text { in } \%\end{array}$ & $\begin{array}{l}2 \text { (Most of the } \\
\text { Time) in } \%\end{array}$ \\
\hline Q3 I feel like crying. & \begin{tabular}{|l|}
36.64 \\
\end{tabular} & \begin{tabular}{|l|}
56.54 \\
\end{tabular} & 6.80 \\
\hline Q5 I feel like leaving home. & 60.73 & 30.36 & 8.90 \\
\hline Q6 I get stomach aches/cramps & 34.03 & 58.11 & 7.85 \\
\hline Q10 I think life isn't worth living. & 70.68 & 22.51 & 6.80 \\
\hline Q14 I have horrible dreams. & 36.64 & 6.80 & 56.54 \\
\hline Q15 I feel very lonely. & 50.78 & 37.17 & 12.04 \\
\hline $\begin{array}{l}\text { Q17 I feel so sad I can't hardly } \\
\text { bear it }\end{array}$ & 39.26 & 45.02 & 15.70 \\
\hline Q18 I feel very bored & 20.94 & 58.11 & 20.94 \\
\hline
\end{tabular}

$50 \%$ of students looked forward to things in life sometimes while $7.32 \%$ never felt that way. It was analysed that $7.32 \%$ adolescents never slept well while the rest either had no issues or had problems sometimes. About $66.49 \%$ of the students liked going out and $94.3 \%$ of the students had lots of energy most of the times or sometime. Only $5.7 \%$ felt that they never had lots of energy. It was seen that $3.14 \%$ of students never enjoyed their food while the rest either enjoyed their meal most of the time or sometimes. Half of the students felt that they could stand up for themselves most of the times while $8.37 \%$ of the students never felt that way. $29.8 \%$ of the adolescents felt they were never good at the things they do while the majority never felt along those line or had such feelings sometimes. Only $3.6 \%$ of the students never enjoyed things as much as they used to. Majority of students $85.34 \%$ liked talking with friends and family most of the time while $1.5 \%$ never felt that way. Most of them $91.6 \%$ could be cheered up easily most of the times or sometimes while $8.3 \%$ never get easily cheered up.

In response to the negative questions, it was seen that $6.8 \%$ students felt like crying all the time while the majority $(56.5 \%)$ felt like crying sometimes. The majority that is $60.73 \%$ of students have never felt like leaving home while $8.9 \%$ of students have felt like leaving home. $58.11 \%$ of students get stomachache sometimes and $7.85 \%$ of students have stomach aches most of the time. $70.6 \%$ of students felt life isn't worth living and $56.54 \%$ students had horrible dreams most of the time and $36.64 \%$ never had nightmares. $12.04 \%$ of the students felt very lonely most of the times and the majority $(50.78 \%)$ never felt that way. $15.70 \%$ of adolescents felt unbearably sad while the majority (45\%) felt such intense emotions sometimes. $20.94 \%$ of the adolescents felt bored most of the times while the same percentage of the students experience the other end of the spectrum i.e. never feel bored.

\section{DISCUSSION}

Mental health among adolescents assumes a quintessential role in determining the mental apparatus with which they face life as adults. Efforts taken to achieve it complement the interventions taken to help correct emotional and behavioural problems among the youth.(8) Proper nutrition, exercise and at the school level helping students in cultivating hobbies that engages them when bored, mental health counseling, a body within the school that hears and counsels students who have experienced trauma or abuse of any kind are some ways to maintain positive mental health. At the community level, teen centers organized by NGOs can help teens to utilize their spare time to identify and develop their passion in sports, literature, debates etc. which in turn prevents them from getting absorbed into the drug-taking subculture.

The adolescent wellbeing scale was selected as the tool to screen for depression because of the following merits. This self-reporting scale is easy to administer and allows for quick assessment of a large study population. It is easy to understand and does not suffer from the setbacks of cultural or gender differences. It has been validated in the 1980s and serves as reliable screening tool.

The results from this study show that incidence of depression in female adolescents $(22.1 \%$ of female students were depressed) is higher than that of male students $(17.7 \%$ 
of male students were depressed) by a marginal difference. This is in concordance with the results obtained from other studies such as the one conducted in Iran(4) and India, which sought to describe the evolution of adolescent mental health in rapidly changing socioeconomic environment. This Indian study also identified female gender as a risk factor for depression like many other international studies.(9)

$33 \%$ of 13-year-old adolescents were found to be depressed. This percentage is higher than that calculated for students younger than 13 years of age $(27.2 \%$ and $23.8 \%$ among 11- and 12-years old adolescents respectively). This trend of rise in the occurrence of depression with age has been recorded in literature from all over the world. A Norwegian study conducted at Nord- Trøndelag country found the scores of the Hospital Anxiety and Depression Scale (HADS) and prevalence rates of depression to increase with age.(10) Indian studies like the one conducted in Chennai with subjects from Chennai Urban Rural Epidemiology Study (CURES) using Patient Health Questionnaire (PHQ) also found an increasing trend in the prevalence of depression with age among both genders $(\mathrm{p}<0.001)$. $^{(11)}$

One of the demographic details explored in this study is the presence of siblings in the maintenance of mental health. This is a dynamic entity with no mere dichotomous results on mental health. Presence of a family in life has been widely regarded as the groundwork on which one's personality develops informed by mental strengths or deficits that this biological and social unit of society has cultivated or aggravated. It serves as placenta filtering the unwanted, contributing to effective functioning in society.(9) Having siblings of relatable age can help specifically to release undue stress accumulated from age specific tribulations. This study found that $27.7 \%$ students without a sibling while $27 \%$ of students with sibling (s) had depression. This statistical result supports the role of mental cushioning provided by family. But it cannot be interpreted as simply with statistical superiority, for there are many factors in play that define the effect of family. Existence of social bond that for allows free communication helps to overcome the stress and strains of life and attain a mental equilibrium with insults incurred living life and function with optimal mental health without diminishing social and work life. The existence of this buffer system is supported by a study that sought to understand the role of sibling support in conflict families. It found that self-esteem assessed through questionnaire, from high- conflict family homes with high sibling support was more positive when compared to that of similar families with only- child.(12) A study conducted among 14-17 years adolescents in Puducherry also concluded that number of siblings accounted for differences in anxiety and emotional ties.(13)

$7.32 \%$ of students felt that their sleep has been affected on a daily basis. An American study had yielded results which suggests reduced quantity of sleep increases the risk of major depression which in turn sets in a viscous loop by serving as risk factor for decreased sleep.(14) $8.3 \%$ felt that they could not stand up for themselves and $29.8 \%$ students felt that they were not good at what they do, most of the times. This feeling is common among this age group as adolescence is the period of experimentation. This period provides maximum exposure to students morally and intellectually, so it is fairly normal to feel inadequate until one stumbles upon a domain in which he or she finds satisfying aptitude.
$56.5 \%$ had nightmares most of the times. A study conducted in the UK on college students using the Oxford sleep survey compared the sleep parameters of clusters that arose based on dimensional measures of psychiatric symptoms such as hallucination, paranoia and depression etc. It found that insomnia and nightmare severity increase the risk for symptoms of severe mental illness.(15) $12.04 \%$ of the students felt lonely most of the times. Loneliness among adolescents can stem from deprivation of the much-needed care and affection from family or facing rejection by peers which deprives one off any kind of attachment or acceptance. This has been explored by a study, which produced results that suggested that clique (Friendship based groups) isolation resulted in escalation of depressive symptoms through loneliness.(16) $58.1 \%$ and $7.8 \%$ of students felt that they had stomach-ache or abdominal cramps sometimes and most of the times respectively. In adolescent females it may be due to dysmenorrhea. It can also be a somatic manifestation of mental stress as seen in irritable bowel syndrome. A study conducted among children who were between 8-15 years found that those with functional recurrent abdominal pain (RAP) were more likely to be diagnosed with psychiatric disorder such as anxiety and depression. The study concluded that examination and treatment for anxiety and/or depressive disorders can function as a suitable intervention for alleviation of functional RAP.(17)

\section{Limitations}

The problem with such self-reporting tool is that the prevalent transient state of mind of student, informed by the events of the day of issue of the questionnaire, can easily influence the replies and provide a distorted insight into their mental health. Disinterested students do not provide reliable responses. Other demographic details such as nativity, economic status of the family, broken family due to death or divorce of parent and history of physical or sexual abuse that point towards stressors that caused or precipitated depression were not collected. Some other problems faced during the study were the inability to access the students between 14 to 16 years of age, who were due to write their examinations during the week of data collection.

\section{CONCLUSIONS}

The results from the study show that $22.1 \%$ of female students were depressed and this is higher when compared to the percentage of depressed male students. 33\% of 13-year-old adolescents were found to be depressed. The study also shows a trend of rise in the occurrence of depression with age. Maintaining mental health does not entail provision of an environment without any stress. It rather demands the need for support in the form of family, friends, teachers (social interaction) that serves as a mental cushion aiding in coping and resilience with any stress or strains of life. Timely identification by periodic screening and therapeutic interventions with the aid from professionals, family and community can help adolescents maintain an equilibrium between oneself and surrounding that forms the cornerstone of healthy adulthood. 


\section{REFERENCES}

[1] Rice F, Harold G, Thapar A. The genetic aetiology of childhood depression: a review. Journal of Child Psychology and Psychiatry 2002;43(1):65-79.

[2] Singh K, Bassi M, Junnarkar M, et al. Mental health and psychosocial functioning in adolescence: an investigation among Indian students from Delhi. Journal of Adolescence 2015;39:59-69.

[3] Kim K, Ryu E, Chon MY, et al. Internet addiction in Korean adolescents and its relation to depression and suicidal ideation: a questionnaire survey. International Journal of Nursing Studies 2006;43(2):185-92.

[4] Mohammadi MR, Alavi SS, Ahmadi N, et al. The prevalence, comorbidity and socio-demographic factors of depressive disorder among Iranian children and adolescents: to identify the main predictors of depression. Journal of Affective Disorders 2019;247:1-0.

[5] Keyes CL. Mental health in adolescence: Is America's youth flourishing? American Journal of Orthopsychiatry 2006;76(3):395-402.

[6] Thapar A, Collishaw S, Pine DS, et al. Depression in adolescence. The Lancet 2012;379(9820):1056-67.

[7] Garland AF, Zigler EF. Psychological correlates of helpseeking attitudes among children and adolescents. American Journal of Orthopsychiatry 1994;64(4):586-93.

[8] Birleson P. The validity of depressive disorder in childhood and the development of a self-rating scale: a research report. Journal of Child Psychology and Psychiatry 1981;22(1):73-88.

[9] Aggarwal S, Berk M. Evolution of adolescent mental health in a rapidly changing socioeconomic environment: a review of mental health studies in adolescents in India over last 10 years. Asian Journal of Psychiatry 2015;13:312.

[10] Stordal E, Krüger BM, Dahl NH, et al. Depression in relation to age and gender in the general population: the Nord-Trøndelag Health Study (HUNT). Acta Psychiatrica Scandinavica 2001;104(3):210-16.

[11] Poongothai S, Pradeepa R, Ganesan A, et al. Prevalence of depression in a large urban South Indian populationThe Chennai Urban Rural Epidemiology Study (CURES70). PLoS One 2009;4(9):e7185.

[12] Caya ML, Liem JH. The role of sibling support in highconflict families. American Journal of Orthopsychiatry 1998;68(2):327-33.

[13] Deb S, Sathyanarayanan P, Machiraju R, et al. Are there differences in the mental health status of adolescents in Puducherry? Asian Journal of Psychiatry 2017;27:32-9.

[14] Roberts RE, Duong HT. The prospective association between sleep deprivation and depression among adolescents. Sleep 2014;37(2):239-44.

[15] Sheaves B, Porcheret K, Tsanas A, et al. Insomnia, nightmares and chronotype as markers of risk for severe mental illness: results from a student population. Sleep 2016;39(1):173-81.

[16] Witvliet M, Brendgen M, Van Lier PA, et al. Early adolescent depressive symptoms: prediction from clique isolation, loneliness, and perceived social acceptance. Journal of Abnormal Child Psychology 2010;38(8):104556.

[17] Campo JV, Bridge J, Ehmann M, et al. Recurrent abdominal pain, anxiety and depression in primary care. Pediatrics 2004;113(4):817-24. 